\title{
Mesoporous Ce-doped Ti:Ash Photocatalyst Investigation in Visible Light Photocatalytic Water Pretreatment Process
}

\author{
Abdulkarim Abdulrahman Mohamed Suliman', Ruzinah Isha, ${ }^{1, *}$, Mazrul Nizam Abu Seman ${ }^{1}$, \\ Abdul Latif Ahmad ${ }^{2}$, Jamil Roslan ${ }^{1}$ \\ ${ }^{1}$ Faculty of Engineering Technology of Chemical and Process, Universiti Malaysia Pahang, Lebuhraya \\ Tun Razak, 23600 Kuantan Pahang, Malaysia. \\ ${ }^{2}$ School of Chemical Engineering, Universiti Sains Malaysia, Engineering Campus, 14300 Nibong \\ Tebal, Pulau Pinang, Malaysia.
}

Received: 10th January 2020; Revised: $3^{\text {rd }}$ April 2020; Accepted: $4^{\text {th }}$ April 2020; Available online: $30^{\text {th }}$ July 2020; Published regularly: August 2020

\begin{abstract}
The treatment of organic pollutants in water including semiconductor photocatalysis is a promising approach to disinfect water. The objective of this study is to investigate the effect of Ce loaded on mesoporous Ti:Ash catalyst for water pretreatment process. The mesoporous Ti:Ash catalyst that doped with Ce was synthesized through wet impregnation method with 5\%,10\%, and 15\% weight percentage of Ce doped on 40:60 Ti:Ash. The photocatalytic properties were characterized through X-ray powder diffraction, scanning electron microscopy with energydispersive X-ray spectroscopy, $\mathrm{N}_{2}$ adsorption-desorption studies and diffuse reflectance UV-vis absorption spectroscopy. It is found that the Ti:Ash nanocomposites doped with Ce shifted the light absorption band-edge position to the visible region. Moreover, the Ce doped Ti:Ash has large surface area and pore diameter. The Ce doping could significantly improve the absorption edge of visible light and adjust the cut-off absorption wavelength from $404 \mathrm{~nm}$ to 451,477 and $496 \mathrm{~nm}$ for 5\%,10\% and 15\% Ce-doped mesoporous Ti:Ash catalysts, respectively. As the Ce doping ratio increased, the band gaps decreased from $3.06 \mathrm{eV}$ to $2.53 \mathrm{eV}$. The most contaminant reduction up to 45\% was achieved when Ti:Ash:Ce 40:55:5 was used. Higher Ce loading on the photocatalyst may reduce the photocatalyst performance because supernumerary metal loading on $\mathrm{TiO}_{2}$ can block $\mathrm{TiO}_{2}$ defect sites which are necessary for the adsorption and photoactivation. The OPFA also acts as an adsorbent for some pollutants besides, reducing the water salinity. It can be deduced that the hybrid $\mathrm{TiO}_{2}$ photocatalyst that synthesized with OPFA and doped with Ce has huge potential to treat seawater prior to commercial seawater desalination process. Copyright (C) 2020 BCREC Group. All rights reserved
\end{abstract}

Keywords: Cerium; Humic acid; Palm oil fiber ash; Photocatalysis; Titanium dioxide; seawater pretreatment

How to Cite: Suliman, A.A.M., Isha, R., Seman, M.N.A., Ahmad, A.L., Roslan, J. (2020). Mesoporous Ce-doped Ti:Ash Photocatalyst Investigation in Visible Light Photocatalytic Water Pretreatment Process. Bulletin of Chemical Reaction Engineering \& Catalysis, 15(2), 367-378 (doi:10.9767/bcrec.15.2.7055.367-378)

Permalink/DOI: https://doi.org/10.9767/bcrec.15.2.7055.367-378

\section{Introduction}

Palm oil is important agriculture Malaysia commodity. Oil palm fiber ash (OPFA) can be found in the boiler from palm oil production. A poorly managed of OPFA in the boiler may

* Corresponding Author.

E-mail: ruzinah@ump.edu.my (R. Isha);

Telp: +6095492891, Fax: +6095492889 cause fouling. The OPFA is rich in silica $(42 \%)$ and the carbon content in the biomass as is about $7.93 \%[1,2]$. Meanwhile, titanium dioxide $\left(\mathrm{TiO}_{2}\right)$ shows an excellent degradation rate for organic pollutants in air and water because of its unique properties, such as photostability, low toxicity, availability and reusability [3-5]. Photocatalytic degradation systems using fine $\mathrm{TiO}_{2}$ powder under UV irradiation have been widely investigated. However, $\mathrm{TiO}_{2}$ has not yet been 
successfully used as a commercial catalyst because of limitations of the light wavelength range to activate catalysts [6]. UV that reaches Earth is represented by less than $\sim 4 \%$ compared with $\sim 45 \%$ of visible light. The fast recombination of a photogenerated hole-electron pair results in a low photocatalytic efficiency with pure titanium [7]. Undesirable electron and hole recombination and low efficiency under irradiation in the visible region are two main drawbacks associated with the use of pure $\mathrm{TiO}_{2}$ [8-10]. Shifting the light absorption band-edge position to the visible region should be continuously enhanced, and a high photoreaction rate of $\mathrm{TiO}_{2}$ should be obtained. $\mathrm{A} \mathrm{TiO}_{2}$ photocatalyst that hybrid with oil palm fiber ash (OPFA) used in seawater pre-treatment processes is a new approach in photocatalyst development. The combination of $\mathrm{TiO}_{2}$ and OPFA alleviates seawater contamination; OPFA acts as an adsorbent of some pollutants and eliminates water salinity where Ti:Ash 40:60 has shown excellent performance in the degradation of humic acid in artificial seawater (ASW) under UV light [1,11]. The surface of $\mathrm{TiO}_{2}$ and its properties have been extensively modified through doping or co-deposition of metals with $\mathrm{TiO}_{2}$ by different methods to reinforce photocatalytic activities [12-15].

The introduction of rare-earth metal elements can remarkably enhance photocatalytic efficiency. However, this method is limited due to high costs [16-18]. The photocatalytic activity of $\mathrm{TiO}_{2}$ can be significantly improved by doping with lanthanide ions/oxides because lanthanide ions can form complexes with various Lewis bases through the interaction of functional groups with their f-orbital [19,20]. Amongst lanthanide oxides, Ce exhibits desirable properties as a dopant because it increases oxygen vacancy formation with the high mobility of oxygen species [21]. Liu et al. reported that $\mathrm{CeO}_{2-\mathrm{y}}-\mathrm{TiO}_{2}$ powders can shift the UV absorption band of $\mathrm{TiO}_{2}$ to a visible light range [22,23]. Aman et al. claimed that the activity of a $\mathrm{Ce}-\mathrm{TiO}_{2}$ photocatalyst depends on the presence of $\left(\mathrm{Ce}^{3+} / \mathrm{Ce}^{4+}\right)$ and the absorption of visible light [24]. In the same context, Makdee et al. reported that, doped $\mathrm{TiO}_{2}$ with cerium improved photocatalytic activity due to the creation of new energy levels by $\left(\mathrm{Ce}^{3+} / \mathrm{Ce}^{4+}\right)$ and oxygen vacancy under the $\mathrm{TiO}_{2}$ conduction band, which can decrease the charge recombination through trapping the electrons [25]. In synthesized materials, an increasing Ce content shifts light absorption to the visible region and shows a high surface area [6]. Furthermore, excited electrons are trapped by $\mathrm{Ce}^{4+}$ and transferred to the adsorbed $\mathrm{O}_{2}$ molecules to produce superoxide anion radicals [26]. Therefore, doping $\mathrm{TiO}_{2}$ with Ce introduces a new energy level between valence and conduction bands, leading to a reduction in the band gap of nano $\mathrm{TiO}_{2}$ and allowing the use of light with a wavelength of over $380 \mathrm{~nm}$ (visible light).

This paper presents the effect of OPFA and Ce addition in $\mathrm{TiO}_{2}$ photocatalyst to treat humic acid contaminated seawater pretreatment. The hybrid photocatalyst was synthesized from Ti:Ash 40:60 with a different mass ration of Cerium 5\%, 10\%, and 15\% wt., through wet impregnation method, characterized and tested at various times in a 1-L reactor under visible light irradiation. The photocatalysts were characterized by X-ray diffraction (XRD), surface area analysis (BET), Scanning Electron Microscopy (SEM), Energy Dispersive X-Ray Spectroscopy (EDX), and UV-Vis Diffuse Reflectance Spectroscopy.

\section{Materials and Methods}

\subsection{Catalyst Preparations}

The materials to prepare Ti:Ash was described in our previous study [9]. The support of the photocatalyst was prepared where the OPFA was calcined at $600{ }^{\circ} \mathrm{C}$, ground and sieved to a particle size less than $125 \mu \mathrm{m}$. Then, the Ce-doped $\mathrm{TiO}_{2}$ materials with different mass percentages of cerium $(5,10$, and 15 $\%(\mathrm{w} / \mathrm{w}))$ were prepared via wet impregnation method. Cerium(III) nitrate hexahydrate (Ce $\left.\left(\mathrm{NO}_{3}\right)_{3} \cdot 6 \mathrm{H}_{2} \mathrm{O}\right)$ was used as metal cations source. An amount of cerium(III) nitrate and oil palm fiber ash (OPFA) and $\mathrm{TiO}_{2}$ were prepared at ratio of Ti:Ash:Ce to 40:55:5, 40:50:10, and 40:45:15. Firstly, the desired amount of $\left(\mathrm{Ce}\left(\mathrm{NO}_{3}\right)_{3} \cdot 6 \mathrm{H}_{2} \mathrm{O}\right)$ was dissolved in $100 \mathrm{~mL}$ of distilled water and stirred. Then, $\mathrm{TiO}_{2}$ and OPFA were gradually added to the solution and stirred for approximately $15 \mathrm{~min}$ at $80^{\circ} \mathrm{C}$ for $4 \mathrm{~h}$. The slurry mixture was dried in an oven at $120^{\circ} \mathrm{C}$ overnight. The dried materials were calcined in a furnace at $500{ }^{\circ} \mathrm{C}$ for $4 \mathrm{~h}$. All the prepared solids were ground and sieved to a particle size less than $125 \mu \mathrm{m}$. The catalyst was denoted as Ti:Ash:Ce x:y:z, where $\mathrm{x}, \mathrm{y}$ and $\mathrm{z}$ represent the mass ratios of $\mathrm{TiO}_{2}$, OPFA and $\mathrm{Ce}$, respectively.

\subsection{Catalyst Characterization}

The microstructure of the doped photocatalyst was characterized using XRD (Rigaku Miniflex II) that equipped with a $\mathrm{Cu} \mathrm{K} \alpha$ source at a wavelength $(\lambda)$ of $1.5405 \AA$ at $15 \mathrm{~mA}, 30$ 
$\mathrm{kV}$ and scanned in the $2 \theta$ range of $10^{\circ}-80^{\circ}$ at 4 $\mathrm{min}^{-1}$. The specific surface area $\left(\mathrm{m}^{2} \cdot \mathrm{g}^{-1}\right)$, pore size $(\mathrm{nm})$ and total pore volume $\left(\mathrm{cm}^{3} \cdot \mathrm{g}^{-1}\right)$ of each photocatalyst were analyzed via $\mathrm{N}_{2}$ adsorption-desorption by using Micromeritic apparatus in which the catalyst was outgassed at $200{ }^{\circ} \mathrm{C}$ for $6 \mathrm{~h}$ prior to analysis. The absorption spectra of the synthesized materials were determined in the scan range of $200-800 \mathrm{~nm}$ by using a UV-vis spectrophotometer (Shimadzu model 2450), and the band gap energies of the prepared catalysts were calculated using a $\mathrm{Ku}$ belka-Munk module [24]. The surface morphology of the prepared photocatalysts was characterized through SEM. Meanwhile, the elements analysis was identified through EDX (QUANTA 450).

\subsection{Photocatalytic Water Pretreatment Proce- dure}

The sample of contaminated seawater was prepared by dissolving the $1 \mathrm{~g}$ of Humic acid in one $\mathrm{L}$ of deionized water, followed by addition of 2 pellets of $\mathrm{NaOH}$ to prepare a stock solution Then, $15 \mathrm{ml}$ of stock solution was added to one $\mathrm{L}$ of deionized water with $30 \mathrm{~g}$ of $\mathrm{NaCl}$. The solution was mixed well with a stirrer to ensure that all salts are dissolved.

A 1 L-capacity borosilicate reactor was used to conduct the photocatalytic reaction on water sample under visible light irradiation (Figure 1). The reactor was covered with aluminium plate to increase light intensity and prevent energy loss from the photoreactor system during the reaction. The reactor was placed in a black box to avoid the interference of external light during the reaction. The reactor was equipped with a visible light $420 \mathrm{~nm}$ wavelength lamp.

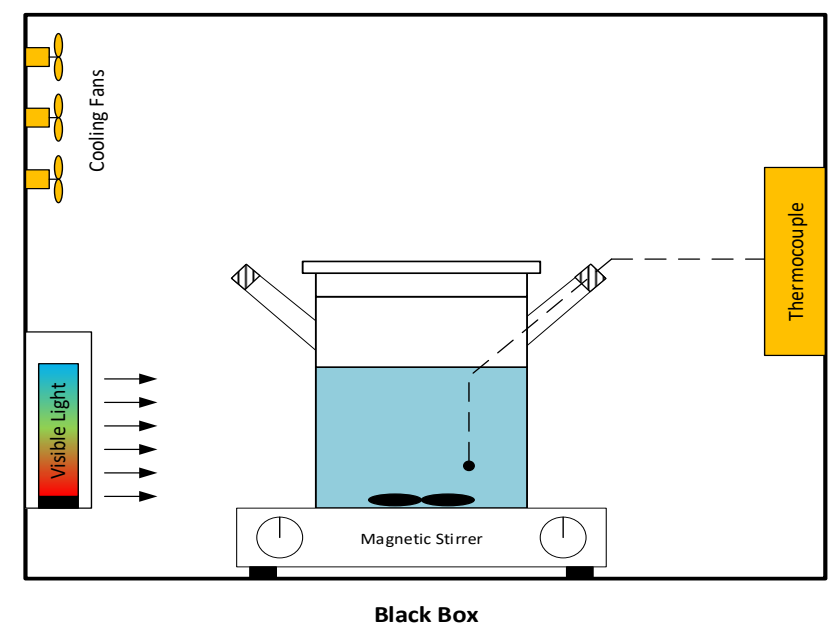

Figure 1. Schematic diagram of the batch photocatalytic reactor set up.
Each run was performed for 1, 2, 3, and $4 \mathrm{~h}$ and simultaneously stirred at $300 \mathrm{rpm}$ to ensure the solution was well mixed. The ratio of the photocatalyst to the water sample was 1:300 where approximately $2.7 \mathrm{~g}$ of the photocatalyst was added into $800 \mathrm{ml}$ of water sample. After the reaction was conducted, the photocatalyst was filtered from the solution. A COD digestion high-range reagent vial (435 COD HR) was used to determine the organic compound in water sample before and after each run. All the measurements were repeated for three times to ensure data reliability, and the average was obtained.

\section{Results and Discussion}

\subsection{Catalyst Characterization}

The XRD patterns of Ti:Ash:Ce 40:60:0, Ti:Ash:Ce 40:55:5, Ti:Ash:Ce 40:50:10 and Ti:Ash:Ce 40:45:15 are presented in Figure 2. The patterns showed the characteristic diffraction peaks at approximately $2 \theta=25.42,37.24$, $37.87,38.65,62.28,62.76$ and 75.11 which could be perfectly indexed to the (101), (103), (004), (112), (213), (204) and (215) crystal faces of the anatase phase of $\mathrm{TiO}_{2}$ (JCPDS: 9015929), respectively. Same observation of diffraction peaks of anatase was also reported by several researchers $[9,18,27]$. The crystallite size of the synthesized materials was calculated by using Scherrer's equation from the (101) crystal plane of the anatase phases at 44.8 , 50.8, 51.6 and $47.2 \mathrm{~nm}$ for Ti:Ash:Ce 40:60:0, Ti:Ash:Ce 40:55:5, 40:50:10 and 40:45:15, respectively. Crystal size increased as the Ce dopant concentration increased from $5 \%$ to $10 \%$; however, as the concentration further increased (15\%), the particle size decreased to



Figure 2. XRD results of synthesized photocatalysts. 
$42.4 \mathrm{~nm}$. Crystal size decreased as dopant concentration increased because Ce crystals on a $\mathrm{TiO}_{2}$ lattice surface suppressed the crystallite growth of $\mathrm{TiO}_{2}$ nanoparticles. Myilsamy et al. also claimed that particle size decreases as dopant concentration increases because $\mathrm{CeO}_{2}$ crystals prevent crystallite growth [20]. The XRD profile of the synthesized materials revealed that Ce species should be in the form of $\mathrm{CeO}_{2}$ modified on a $\mathrm{TiO}_{2}$ surface.

This finding may be also due to the high dopant concentration of Ce. Furthermore, the ceria-titania solid solution appeared at approximately $2 \theta=48.20,54.02$, and 68.74. Another solid solution of a ceria-silica peak was shown at approximately $2 \theta=60.11$ with crystal sizes of $65.5,31.6$, and $21.5 \mathrm{~nm}$ for $5 \%, 10 \%$, and $15 \%$ of Ce loaded, respectively. Thus, it can be deduced that an increased Ce-doped concentration caused a decrease in the crystal size of the solid solution of ceria-silica. The XRD patterns of ash (OPFA) showed that the characteristic peaks of the crystalline phase at approximately $2 \theta=20.96,40.38$, and 50.21 corresponded to quartz.

Figure 3a shows the diffuse reflectance UVvis absorption spectra of Ti:Ash:Ce. Doping Ce on Ti:Ash could significantly influence the absorption of light and band gap. Figure 3 a also reveals that the red shift of the increased doping concentration of $\mathrm{Ce}$ was better than that of a Ti:Ash:Ce 40:60:0 hybrid photocatalyst. The cut-off absorption wavelength was expended to the visible areas by doping Ce with Ti:Ash.

The band gap energy of the synthesized material was calculated using the Kubelka-Munk function [5,6]. Figure 3b illustrates that band gap energy decreased as the doping ratio increased. It can be seen that Ti:Ash:Ce 40:60:0, Ti:Ash:Ce 40:55:5, 40:50:10 and 40:45:15 had onsets of absorbance of 3.06, 2.72, 2.61 and $2.53 \mathrm{eV}$, respectively. As the doping ratio increased from $0 \%$ to $15 \%$, the cut-off wavelength expended from $404 \mathrm{~nm}$ to $496 \mathrm{~nm}$. Thus, the band gap decreased from $3.06 \mathrm{eV}$ to $2.53 \mathrm{eV}$.

The cut-off wavelength and the band gap energy of each sample are tabulated in Table 1. The result confirmed that doping $\mathrm{Ce}$ with Ti:Ash 40:60 could reduce the wideness of the forbidden band of $\mathrm{TiO}_{2}$ nanomaterials. The band gap decreased because the doped Ce ions in $\mathrm{TiO}_{2}$ nanopowders cause lattice distortion and introduce impurity to the forbidden band of $\mathrm{TiO}_{2} \quad[6,28]$. Whereas, the electron can transfer in the valence band or conduction band between the doping and raw materials $[29,30]$. Tong et al. reported that the energy of the conduction band in $\mathrm{TiO}_{2}$ is larger than that of the $4 \mathrm{f}$ orbital energy level of $\mathrm{Ce}$; thus, the $4 \mathrm{f}$ orbital of Ce plays a crucial role in generating charge carries $\left(\mathrm{e}^{-}, \mathrm{h}^{+}\right)$under visible irradiation [31,32].
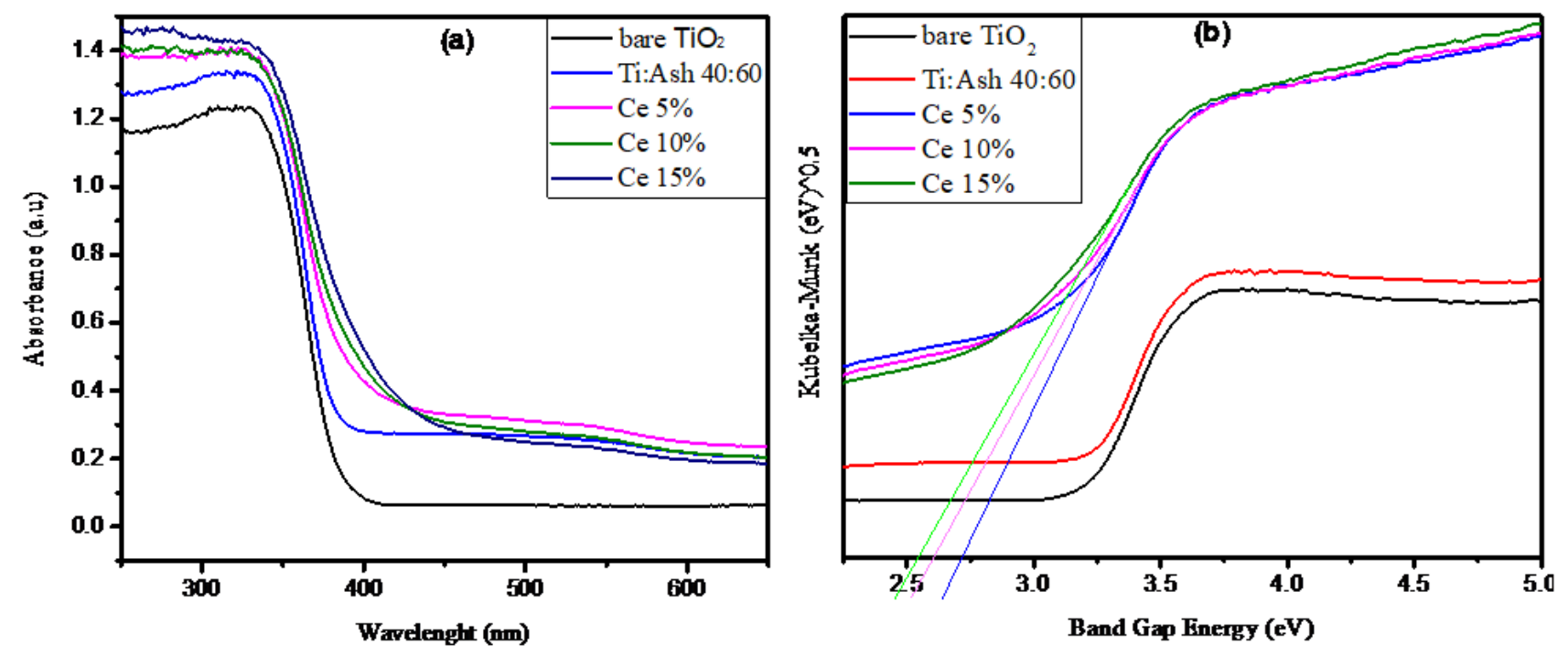

Figure 3. (a) Results obtained from UV-Vis DRS. (b) Kubelka-Munk plot for band gap.

Table 1. Cut-off wavelength and band gap of Ti:Ash 40:60 doped with different ratio of Ce.

\begin{tabular}{lcccc}
\hline Samples & Ti:Ash 40:60 & Ti:Ash:Ce 40:55:5 & $\begin{array}{c}\text { Ti:Ash:Ce } \\
40: 50: 10\end{array}$ & $\begin{array}{c}\text { Ti:Ash:Ce } \\
40: 45: 15\end{array}$ \\
\hline Cut-off wavelength (nm) & 404 & 451 & 477 & 496 \\
Band gap (eV) & 3.06 & 2.72 & 2.61 & 2.53 \\
\hline
\end{tabular}


The pore structure and specific surface areas of all the samples were investigated on the basis of $\mathrm{N}_{2}$ adsorption-desorption isotherm. As shown in Figure 4, these samples showed type IV isotherms, indicating the mesoporous structure of the samples. The corresponding hysteresis loops were type $\mathrm{H}_{3}$ at a high relative pressure range between 0.65 and 1.0 for Ti:Ash:Ce 40:55:5 and Ti:Ash:Ce 40:50:10. The relative pressure range of Ti:Ash:Ce 40:55:15 was from 0.2 to 1 , suggesting that Ti:Ash:Ce 40:55:15 could be an effective absorbent. The appear- ance of hysteresis loops supports the presence of slit-like pores [16,19].

Table 2 presents the results of BET analysis to determine the surface area, pore volume and pore size of the fresh and spent of Ti:Ash:Ce photocatalyst. The BET surface area of Ti:Ash:Ce 40:60:0 increased from $3.9 \mathrm{~m}^{2} \cdot \mathrm{g}^{-1}$ to $6.1 \mathrm{~m}^{2} \cdot \mathrm{g}^{-1}$ after the reaction. The same pattern of increment was observed in Ti:Ash:Ce 40:55:5 and 40:55:10 photocatalyst as the photocatalyst surface area rose from $11.54 \mathrm{~m}^{2} \cdot \mathrm{g}^{-1}$ to 18.21 $\mathrm{m}^{2} \cdot \mathrm{g}^{-1}$ and from $10.43 \mathrm{~m}^{2} \cdot \mathrm{g}^{-1}$ to $18.06 \mathrm{~m}^{2} \cdot \mathrm{g}^{-1}$,
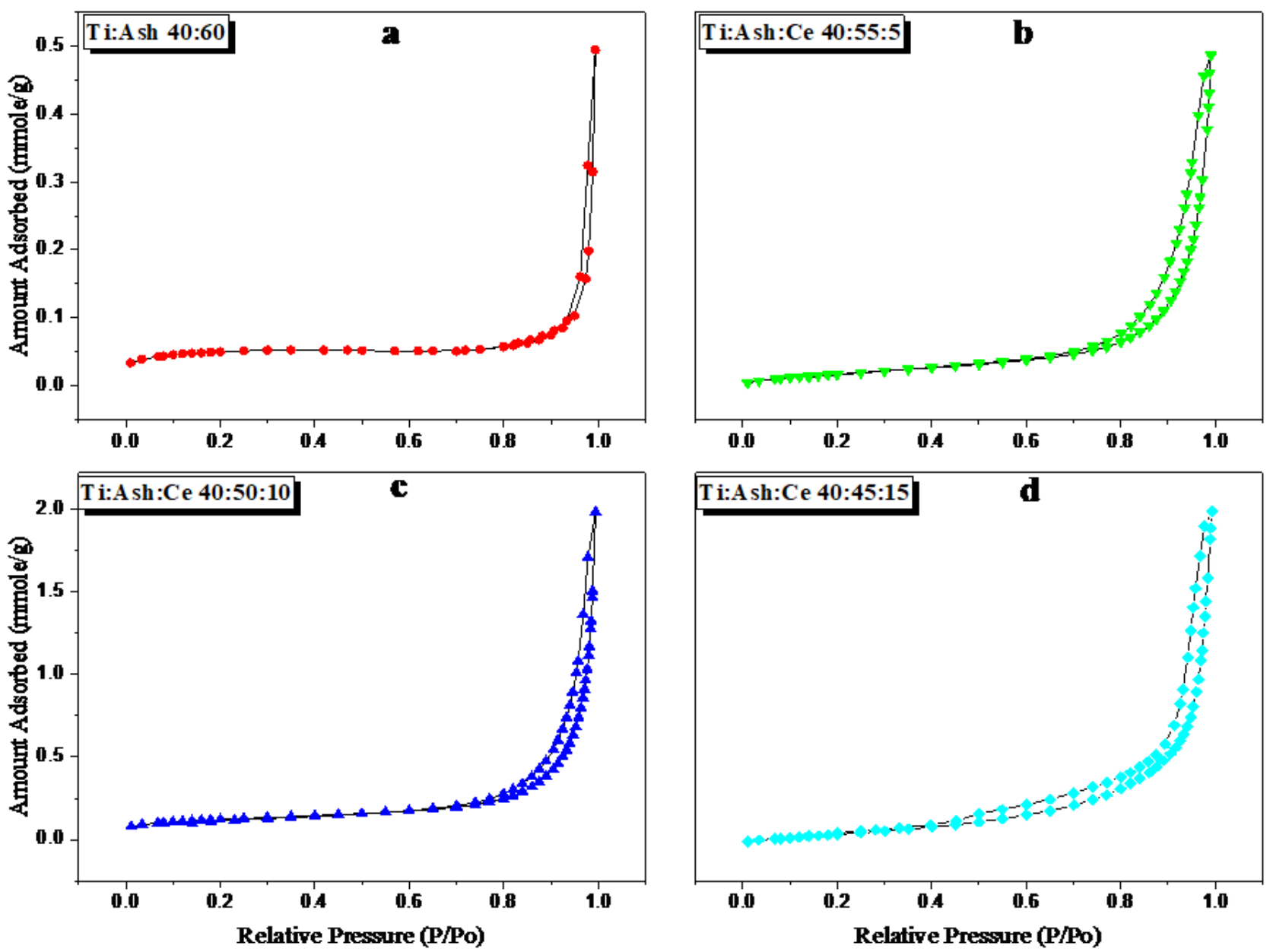

Figure 4. BET adsorption isotherms for the Ce-doped samples, (a) Ti:Ash 40:60, (b) Ti:Ash:Ce 40:55:5, (c) Ti:Ash:Ce 40:50:10, and (d) Ti:Ash:Ce 40:45:15.

Table 2. The microstructure analysis of hybrid Ti:Ash:Ce photocatalysts.

\begin{tabular}{|c|c|c|c|c|c|c|}
\hline \multirow{2}{*}{$\begin{array}{c}\text { Ce loading } \\
(\%)\end{array}$} & \multicolumn{2}{|c|}{$\begin{array}{c}\text { Specific surface area } \\
\left(\mathrm{m}^{2} \cdot \mathrm{g}^{-1}\right)\end{array}$} & \multicolumn{2}{|c|}{$\begin{array}{c}\text { Pore volume } \times 10^{2} \\
\left(\mathrm{~cm}^{3} \cdot \mathrm{g}^{-1}\right)\end{array}$} & \multicolumn{2}{|c|}{$\begin{array}{l}\text { Pore size } \\
\quad(\mathrm{nm})\end{array}$} \\
\hline & Before & After & Before & After & Before & After \\
\hline $0 \% \mathrm{Ce}$ & 3.90 & 6.10 & 7.10 & 3.20 & 21.50 & 17.40 \\
\hline $5 \% \mathrm{Ce}$ & 11.54 & 18.21 & 3.04 & 3.51 & 10.55 & 7.78 \\
\hline $10 \% \mathrm{Ce}$ & 10.43 & 18.06 & 4.50 & 4.17 & 1549. & 9.17 \\
\hline $15 \% \mathrm{Ce}$ & 11.60 & 19.54 & 6.03 & 6.03 & 20.80 & 12.35 \\
\hline
\end{tabular}




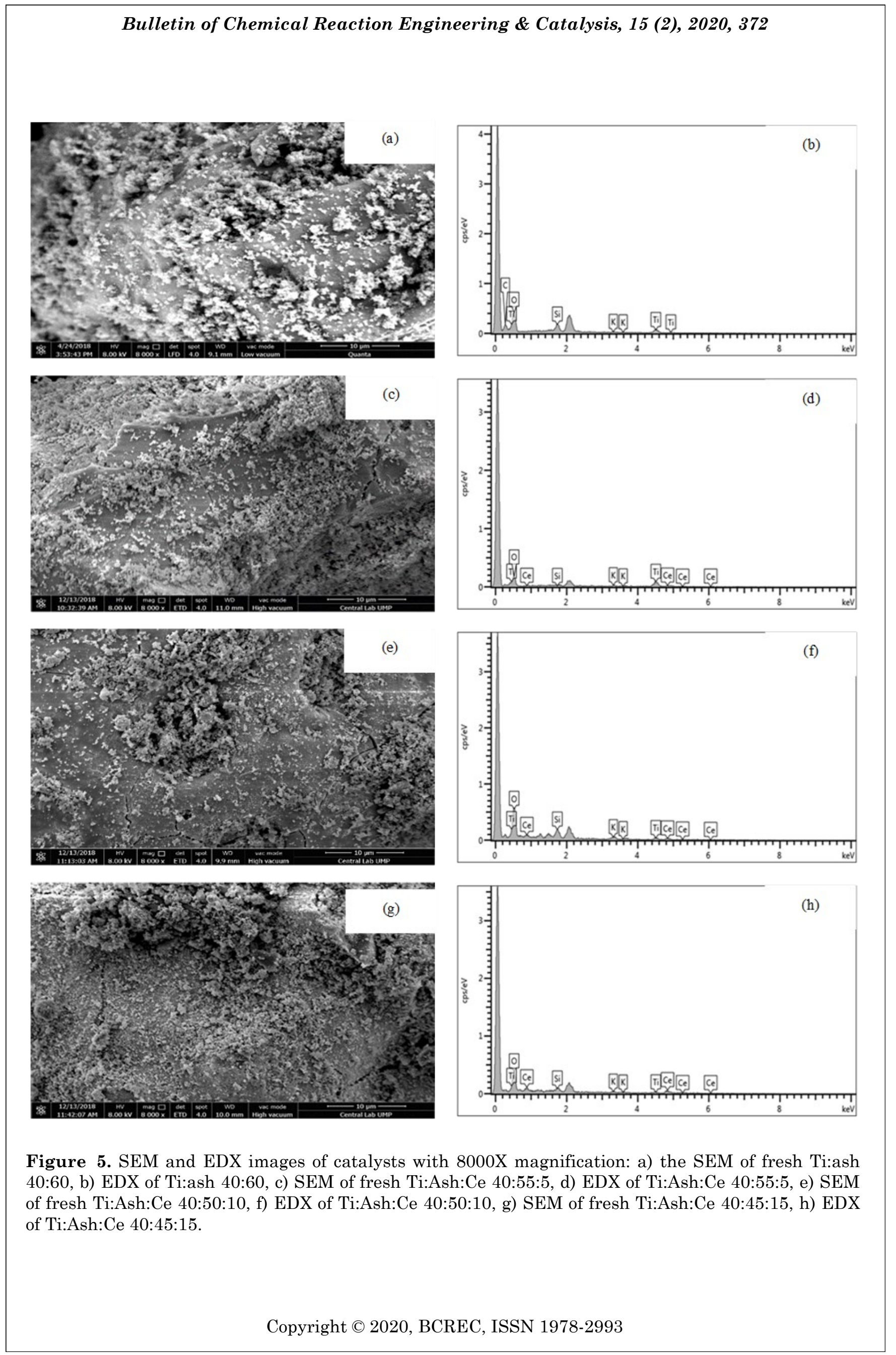


respectively. The surface area of Ti:Ash:Ce 40:55:15 also increased from $11.60 \mathrm{~m}^{2} \cdot \mathrm{g}^{-1}$ to $19.54 \mathrm{~m}^{2} \cdot \mathrm{g}^{-1}$.

The morphological characteristics and phase composition of the photocatalysts were analyzed through SEM and EDX. Whereas, the $\mathrm{TiO}_{2}$ and OPFA were investigated in our previous study [9]. Figure 5a presents the SEM image of the Ti:Ash:Ce 40:60:0, that is, the welldispersed tiny spherical aggregated particles with different diameters. Figures. 5c, 5e, and $5 \mathrm{~g}$ illustrate the images of the as-synthesized samples of Ti:Ash:Ce 40:55:5, 40:50:10 and 40:45:15, respectively. The SEM image of the prepared samples shows the inbuilt mesopore structure in the aggregated particles. Agglomeration was affected by increasing the amount of Ce. Myilsamy et al. similarly reported that the tendency of individual particles of $\mathrm{TiO}_{2}$ to agglomerate is affected by the presence of $\left(\mathrm{Ce}^{4+} / \mathrm{Ce}^{3+}\right)$ and spherical aggregates of particles with varying sizes and large irregular voids distributed amongst the particles [20]. The images also display a well-dispersed of $\mathrm{TiO}_{2}$ and $\mathrm{Ce}$ on the OPFA surface in all the synthesized photocatalysts. This finding indicated that thorough mixing enhanced the dispersion of $\mathrm{TiO}_{2}$ ash and Ce during catalyst preparation. The EDX spectrum of Ti:Ash:Ce 40:60:0 is shown in Figure 5b. The other photocatalyst sample is illustrated in Figures 5d, 5f and $5 \mathrm{~h}$. The Ti, O, Si and Ce peaks were found in the spectra, confirming the presence $\mathrm{Ce}$ in $\mathrm{TiO}_{2}$ nanoparticles.

\subsection{Photocatalytic Degradation of Humic Acid}

Prior to this investigation, when visible light was exposed to the water sample alone, no significant change of water COD and salinity

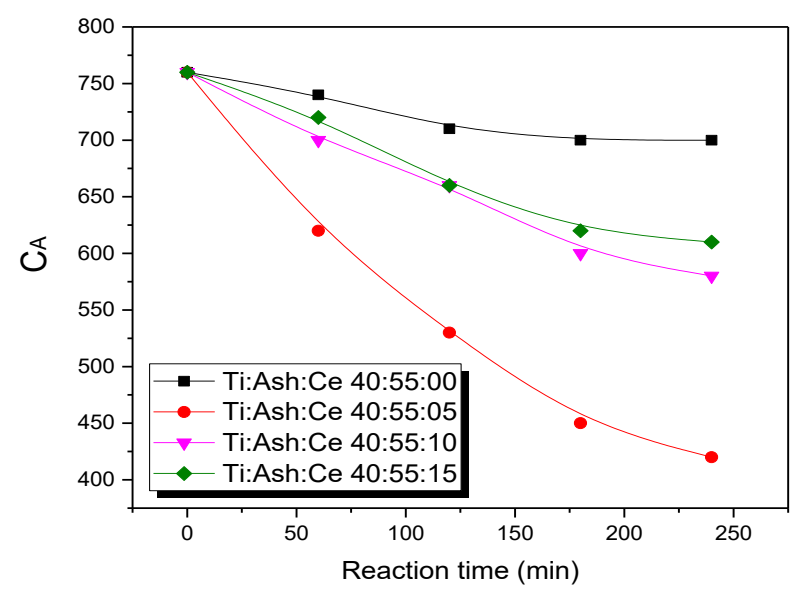

Figure 6. COD profiles of treated water using photocatalysts. were obtained. The Ti:Ash:Ce 40:60:0 was then tested without light irradiation for 240 minutes. It is found that no significant change of COD was observed but a slight decrease of water salinity was observed. This indicates that adsorption of contaminant did not occur.

Figure 6 shows the COD profiles of water samples tested after $240 \mathrm{~min}$ in visible light irradiation. The Ti:Ash:Ce 40:60:0 was tested under visible light to serve as a blank run, no significant change was found. This was because the band gap energy of Ti:Ash:Ce 40:60:0 is $3.06 \mathrm{eV}$ which reactive in UV light. The slight reduction of COD in the first 100 minutes might be caused by the adsorption of contaminants by ash. Oil palm fiber ash (OPFA) has been used as a low-cost substitute adsorbent to eliminate harmful coloration such as malachite green (MG), methylene blue, an anionic dye, direct blue 71 [33-35]. The Langmuir balance isotherm is more accurate than the other isotherm equations to explain the adsorption in the oil-palm shell of aqueous phenol [36,37]. The investigation was done by Kan et al. indicate that the silica content in OPFA might enhance the adsorption ability of photocatalyst in seawater pretreatment [11]. Silica content in OPFA might enhance the catalyst uses in seawater pretreatment by improving adsorbing characteristic. Moreover, appearance salt peaks on spent catalysts support this observation.

Humic acids (HA) constitute a vast majority of natural organic matter (NOM) and are commonly present in natural water and strictly affect its taste and color $[38,39]$. Humic acids are compounds distinguished by high levels of carboxyl $(-\mathrm{COOH})$ and phenolic hydroxyl $(-\mathrm{OH})$ groups bound to aromatic chains. Since they are a very complex mixture, they cannot be represented by a simple formula [40,41]. Humic acid comes from the soil, river, and lake sediments, coral, freshwater, wastewaters, plants and coral skeletons [42]. One of the sources of HA in seawater is aquaculture, This can be done by the addition of humic acid in the formula of the feed, which can lower the accumulation of heavy metals in the fish body $[43,44]$. Humic acids is among the common contaminants that can be found in water source. Humic acid can be degraded into free radicals, such as singlet oxygen, humic-derived peroxy radicals by solvated electron and $\mathrm{OH}^{\circ}$ radicals [4]. The presence of different transition metal oxides, such as: $\mathrm{TiO}_{2}, \mathrm{CuO}, \mathrm{Fe}_{2} \mathrm{O}_{3}$ and $\mathrm{ZnO}$, in OPFA promotes environmentally persistent free radicals in the form of metal 
cations or redox potentials of metal ions $[10,45]$ for contaminants degradations.

As can be seen in Figure 6, a significant decreasing trend of COD reduction was observed when Ti:Ash:Ce 40:55:5 was used. Generally, it was found that a reduction of $18 \%$ of contaminants was observed after tested for $60 \mathrm{~min}$, while $30 \%, 41 \%$, and $45 \%$ was observed after testing for $120 \mathrm{~min}, 180 \mathrm{~min}$, and $240 \mathrm{~min}$ respectively. In contrast, the COD profiles for Ti:Ash:Ce 40:50:10 and Ti:Ash:Ce 40:45:15 photocatalysts showed less activity than Ti:Ash:Ce 40:55:5. When Ti:Ash:Ce 40:50:10 was used, $8 \%, 13 \%, 21 \%$, and $24 \%$ of COD reduction was obtained after testing for $60 \mathrm{~min}, 120 \mathrm{~min}, 180$ min, and $240 \mathrm{~min}$. respectively. Meanwhile, a reduction of $5 \%, 13 \%, 18 \%$, and $20 \%$ was obtained when Ti:Ash:Ce 40:45:15 was used after $60 \mathrm{~min}, 120 \mathrm{~min}, 180 \mathrm{~min}$, and $240 \mathrm{~min}$, respectively.

The highest contaminants reduction was achieved when Ti:Ash:Ce 40:55:5 was used. It might be caused by the Ti:Ash:Ce 40:55:5 photocatalyst band gap energy of $2.72 \mathrm{eV}$, which reactive in visible light. Moreover, excellent $\mathrm{Ce}$ metal distribution on the photocatalyst surface and textural properties might contribute to remarkable performance of Ti:Ash:Ce 40:55:5. The optimum metal loading in the photocatalyst is also important because suitable amount of metal loading enhances the photoactivity of catalysts by increasing the number of electron trapping sites $[14,46]$. In addition, the amount of metal loading is crucial because supernumerary metal loading on $\mathrm{TiO}_{2}$ can block $\mathrm{TiO}_{2}$ defect sites which are necessary for the adsorption and photoactivation of oxygen, thereby reduc-

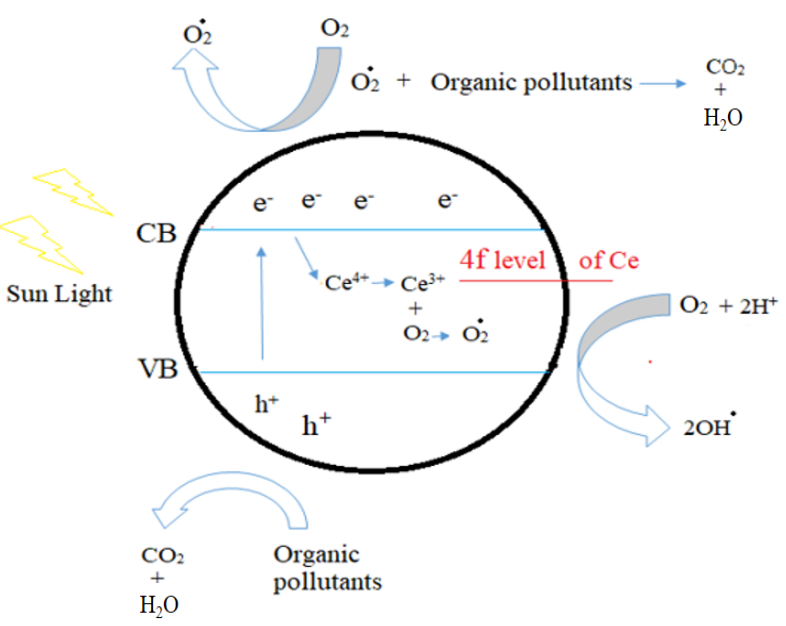

Figure 7. Schematic photocatalysis mechanism of Ti:Ash:Ce photocatalysts. ing the photoactivity of organic degradation $[47,48]$.

\subsection{Possible Catalytic Mechanism}

Numerous studies have been conducted to identify the catalytic mechanism and the reactive species responsible for organic compound degradation. The essential reactive species are electrons (e-), holes $\left(\mathrm{h}^{+}\right)$and hydroxyl free radicals $\left(\mathrm{OH}^{*}\right)$. Thus, $\mathrm{Ce} 4 \mathrm{f}$ level in Ti:Ash:Ce plays a vital role in interfacial charge transfer and restraint of electron-hole recombination, Besides that, The combined interaction between $\mathrm{Ti}$ and Ce metal cations promotes an easy charge transfer on surfaces, accelerating the $\mathrm{Ce}^{3+}$ redox process that is beneficial to oxidation $[7,49]$. Makdee et al. reported that doped $\mathrm{TiO}_{2}$ with cerium improved photocatalytic activity due to the creation of new energy levels by $\mathrm{Ce}^{3+}$ and oxygen vacancy under the $\mathrm{TiO}_{2}$ conduction band, which can decrease the charge recombination through trapping the electrons [25]. Moreover, cerium ions could form complexes with various Lewis bases in the interaction of the functional groups with their f-orbital, which promote the photocatalytic activity either by the presence of redox couple or different optical properties caused by different ions, $\mathrm{Ce}^{3+}[20,50]$.

On the other hand, oxygen has an ability to accept and consume the generated electrons in the photo-degradation reaction and producing free radical species through the following steps:

$$
\begin{aligned}
& \mathrm{Ce}^{3+}+\mathrm{O}_{2} \rightarrow \mathrm{O}_{2}^{\bullet} \\
& e^{-}+\mathrm{O}_{2} \rightarrow \mathrm{O}_{2}^{\bullet}
\end{aligned}
$$

After producing the superoxide free radicals $\left(\mathrm{O}_{2}{ }_{2}\right)$, the second stage of photo-degradation will start to produce the reactive free radical species (hydroxyl radical $\mathrm{OH}^{*}$ ). The process of generating $\mathrm{OH}^{\cdot}$ can occur by two pathways; first $\mathrm{O}_{2}$ present in water is reduced to form $\mathrm{O}_{2}{ }_{2}$, which then reacts with $\mathrm{H}^{+}$to form $\mathrm{OOH}$, followed by rapid decomposition to $\mathrm{OH}^{\cdot}$. The second pathway involves the oxidation of $2 \mathrm{H}^{+}$,

Table 3. The $k$-value for each set of photoreaction with their corresponding $\mathrm{R}^{2}$-value.

\begin{tabular}{ccc}
\hline Photocatalyst & $k\left(\mathrm{~min}^{-1}\right)$ & $\mathrm{R}^{2}$ \\
\hline Ti:Ash:Ce 40:55:05 & 0.0025 & 0.9764 \\
Ti:Ash:Ce 40:50:10 & 0.0012 & 0.9845 \\
Ti:Ash:Ce 40:45:15 & 0.0010 & 0.9623 \\
\hline
\end{tabular}


which aid in the decay of contaminants, as shown in Figure 7 [20,22,51].

$$
\mathrm{O}_{2}^{\bullet}+2 \mathrm{H}^{+} \rightarrow 2 \mathrm{OH}^{\bullet}
$$

Furthermore, the kinetics data for different catalyst Ti:Ash:Ce loadings were determined by using Langmuir-Hinshelwood (LH) rate law model. After fitting data on first order reaction, a typical irreversible reaction in this study can be described by the following equation:

$$
-r_{C O D}=\frac{1}{C_{A}}=k t+\frac{1}{C_{A 0}}
$$

where $-r_{C O D}$ is COD degradation rate (mg. $\left.\mathrm{L}^{-1} \cdot \mathrm{min}^{-1}\right)$ and the $k$ is a specific reaction time $\left(\mathrm{min}^{-1}\right)$. The values of the specific reaction time $k$, and $\mathrm{R}^{2}$ summarized in Table 3.

\section{Conclusions}

The activity of $\mathrm{TiO}_{2}$ for humic acid degradation in water was investigated using photocatalysts of Ti:Ash:Ce which were synthesized at the various mass ratio. The XRD pattern indicates that the crystalline phase of the $\mathrm{TiO}_{2}$ matrix was stable, and new solid solution peaks were achieved after impregnated with $\mathrm{Ce}$ and ash. Furthermore, UV-vis absorption spectroscopy confirmed that Ce loading reduced the energy band gap of photocatalysts from $3.06 \mathrm{eV}$ (Ti:Ash:Ce 40:60:0) to $2.53 \mathrm{eV}$ (Ti:Ash:Ce 40:60:15) which reactive in visible light. The $\mathrm{Ce}$ was well dispersed on the Ti:Ash photocatalyst. It is also found that aggregation and agglomeration of the loaded metal increased when the amount of Ce loading increased. The synthesized photocatalyst exhibited type IV isotherms, indicating the mesoporous structure of the photocatalyst. The Ti:Ash:Ce 40:60:0 exhibited a low activity under visible light irradiation while Ti:Ash:Ce 40:55:5 performed the best with up to $45 \%$ contaminant reduction was achieved. The higher Ce loading on the photocatalyst may reduce the photocatalyst performance because supernumerary metal loading on $\mathrm{TiO}_{2}$ can block $\mathrm{TiO}_{2}$ defect sites which are necessary for the adsorption and photoactivation. It can be deduced that the hybrid $\mathrm{TiO}_{2}$ photocatalyst that synthesized with OPFA and doped with Ce has huge potential to treat seawater.

\section{Acknowledgment}

The authors acknowledge the support of the Universiti Malaysia Pahang (UMP) [RDU1703242 \& PGRS160331] and Ministry of Education, and Bright Star University of Tech- nology, Libya for a PhD scholarship for one of the authors (Abdulkarim Suliman).

\section{References}

[1] Ahmad, T., Danish, M., Rafatullah, M., Ghazali, A., Sulaiman, O., Hashim, R. (2012). The use of date palm as a potential adsorbent for wastewater treatment: a review. Environmental Science and Pollution Research, 19, 1464-1484. DOI: 10.1007/s11356-011-0709-8

[2] Abdullah, N., Sulaiman, F. (2013). The oil palm wastes in Malaysia, in Biomass NowSustainable Growth and Use, ed: InTech.

[3] Aman, N., Mishra, T., Sahu, R.K., Tiwari, J.P. (2010). Facile synthesis of mesoporous N doped zirconium titanium mixed oxide nanomaterial with enhanced photocatalytic activity under visible light. Journal of Materials Chemistry, 20, 10876-10882. DOI: 10.1039/C0JM01342K

[4] Andayani, W., Bagyo, A.N. (2011). $\mathrm{TiO}_{2}$ bead for hotocatalytic degradation of humic acid in peat water R. Indonesian Journal of Chemistry, 11, 253-257.

[5] Chen, C., Ma, W., Zhao, J. (2010). Semiconductor-mediated photodegradation of pollutants under visible-light irradiation. Chemical Society Reviews, 39, 4206-4219. DOI: 10.1039/B921692H

[6] Cheng, Y., Zhang, M., Yao, G., Yang, L., Tao, J., Gong, Z. (2016). Band gap manipulation of cerium doping $\mathrm{TiO}_{2}$ nanopowders by hydrothermal method. Journal of Alloys and Compounds, $662, \quad 179-184$. DOI: 10.1016/j.jallcom.2015.12.034

[7] Fiorenza, R., Bellardita, M., Barakat, T., Scirè, S., Palmisano, L. (2018). Visible light photocatalytic activity of macro-mesoporous $\mathrm{TiO}_{2}-\mathrm{CeO}_{2}$ inverse opals. Journal of Photochemistry and Photobiology A: Chemistry, $\begin{array}{llllllll}3 & 5 & 2\end{array}, \quad 25-34 . \quad$ D O I : 10.1016/j.jphotochem.2017.10.052

[8] Ibhadon, A.O., Fitzpatrick, P. (2013). Heterogeneous photocatalysis: recent advances and applications. Catalysts, 3, 189-218. DOI: 10.3390/catal3010189

[9] Isha, R., Roslan, J., Suliman, A. (2018). Effect of mass ratio of titanium dioxide and oil palm fiber ash $\left(\mathrm{TiO}_{2}\right.$ :Ash) in hybrid photocatalyst on photocatalytic seawater pretreatment. In: Proceedings of The National Conference for Postgraduate Research (NCON-PGR 2018), 124-132.

[10] Jia, H., Zhao, S., Shi, Y., Zhu, L., Wang, C., Sharma, V.K. (2018). Transformation of polycyclic aromatic hydrocarbons and formation of environmentally persistent free radicals on modified montmorillonite: the role of surface 
metal ions and polycyclic aromatic hydrocarbon molecular properties. Environmental Science \& Technology, 52, 5725-5733. DOI: 10.1021/acs.est.8b00425

[11] Kan, W.E., Isha, R. (2016). The effect of light wavelength on water quality in photocatalytic seawater pre-treatment. In: Proceedings of The National Conference for Postgraduate Research (NCON-PGR 2016). 89-94.

[12] Kan, W.E., Roslan, J., Isha, R. (2016). Effect of Calcination temperature on performance of photocatalytic reactor system for seawater pretreatment. Bulletin of Chemical Reaction Engineering \& Catalysis, 11(2), 230-237. DOI: 10.9767/bcrec.11.2.554.230-237

[13] Khan, M.M., Ansari, S.A., Pradhan, D., Ansari, M.O., Lee, J., Cho, M.H. (2014). Band gap engineered $\mathrm{TiO}_{2}$ nanoparticles for visible light induced photoelectrochemical and photocatalytic studies. Journal of Materials Chemistry A, 2, 637-644. DOI: 10.1039/C3TA14052K

[14] Khan, M.R., Chuan, T.W., Yousuf, A., Chowdhury, M., Cheng, C.K. (2015). Schottky barrier and surface plasmonic resonance phenomena towards the photocatalytic reaction: study of their mechanisms to enhance photocatalytic activity. Catalysis Science \& Technology, 5, 2522-2531. D I : 10.1039/C4CY01545B

[15] Kharel, P.L., Cuillier, P.M., Fernando, K., Zamborini, F.P., Alphenaar, B.W. (2018). Effect of Rare-Earth Metal Oxide Nanoparticles on the Conductivity of Nanocrystalline Titanium Dioxide: An Electrical and Electrochemical Approach. The Journal of Physical Chemistry C, 122, 15090-15096. DOI: 10.1021/acs.jpcc.8b02971

[16] Liu, J., Li, H., Li, Q., Wang, X., Zhang, M., Yang, J. (2014). Preparation of cerium modified titanium dioxide nanoparticles and investigation of their visible light photocatalytic performance. International Journal of Photoenergy, 2014, 9. DOI: 10.1155/2014/695679

[17] Liu, L., Ji, Z., Zou, W., Gu, X., Deng, Y., Gao, F. (2013). In situ loading transition metal oxide clusters on $\mathrm{TiO} 2$ nanosheets as cocatalysts for exceptional high photoactivity. Acs Catalysis, 3, 2052-2061. DOI: $10.1021 / \operatorname{cs} 4002755$

[18] Matějová, L., Kočí, K., Reli, M., Čapek, L., Hospodková, A., Peikertová, P. (2014). Preparation, characterization and photocatalytic properties of cerium doped $\mathrm{TiO}_{2}$ : On the effect of Ce loading on the photocatalytic reduction of carbon dioxide. Applied Catalyst B: Environmental, 152, 172-183. DOI: 10.1016/j.apcatb.2014.01.015
[19] Liu, Z., Guo, B., Hong, L., Jiang, H. (2005). Preparation and characterization of cerium oxide doped $\mathrm{TiO}_{2}$ nanoparticles. Journal of Physics and Chemistry of Solids, 66, 161-167. DOI: 10.1016/j.jpcs.2004.09.002

[20] Myilsamy, M., Murugesan, V., Mahalakshmi, M. (2015). Indium and cerium co-doped mesoporous $\mathrm{TiO}_{2}$ nanocomposites with enhanced visible light photocatalytic activity. Applied Catalysis A: General, 492, 212-222. DOI: 10.1016/j.apcata.2014.12.035

[21] Ndinda, E., Park, H., Kim, K.N. (2014). Preparation and characterization of cerium doped titanium dioxide nano powder for photocatalyst. Korean Journal of Materials Research, 24, 33-36. DOI: 10.3740/MRSK.2014.24.1.33

[22] Ng, K.H., Lee, C.H., Khan, M.R., Cheng, C.K. (2016). Photocatalytic degradation of recalcitrant POME waste by using silver doped titania: Photokinetics and scavenging studies. Chemical Engineering, 286, 282-290. DOI: 10.1016/j.cej.2015.10.072

[23] Niu, B., Wang, X., Wu, K., He, X., Zhang, R. (2018). Mesoporous Titanium Dioxide: Synthesis and Applications in Photocatalysis, Energy and Biology. Materials, 11, 1910. DOI: 10.3390/ma11101910

[24] Aman, N., Satapathy, P., Mishra, T., Mahato, M., Das, N. (2012). Synthesis and photocatalytic activity of mesoporous cerium doped $\mathrm{TiO}_{2}$ as visible light sensitive photocatalyst. Materials Research Bulletin, 47, 179-183.

[25] Makdee, A., Unwiset, P., Chanapattharapol, K.C., Kidkhunthod, P. (2018). Effects of Ce addition on the properties and photocatalytic activity of $\mathrm{TiO}_{2}$, investigated by X-ray absorption spectroscopy, Materials Chemistry and Physics, 213, 431-443.

[26] Devi, L.G., Anitha, B. (2019). Effective band gap engineering by the incorporation of Ce, $\mathrm{N}$ and $\mathrm{S}$ dopant ions into the $\mathrm{SrTiO}_{3}$ lattice: exploration of photocatalytic activity under UV/solar light. Journal of Sol-Gel Science and Technology, 94, 50-66. DOI: 10.1007/s10971-019-05074-4.

[27] Zheng, R.R., Li, T.T., Yu, H. (2008) Construction of Indium and Cerium Codoped Ordered Mesoporous $\mathrm{TiO}_{2}$ Aerogel Composite Material and Its High Photocatalytic Activity. Global Challenges, 2, 700118.

[28] Poulios, I., Micropoulou, E., Panou, R., Kostopoulou, E. (2003). Photooxidation of eo$\sin \mathrm{Y}$ in the presence of semiconducting oxides. Applied Catalysis B: Environmental, 41, 345-355. DOI:10.1016/S0926-3373(02)00160-1

[29] Xu, A.W., Gao, Y., Liu, H.Q. (2002). The preparation, characterization, and their photocatalytic activities of rare-earth-doped $\mathrm{TiO}_{2}$ 
nanoparticles. Journal of Catalysis, 207, 151157. DOI: $10.1006 /$ jcat.2002.3539

[30] Zhu, L., Jo, S.B., Ye, S., Ullah, K., Oh, W.C. (2014). Fabrication of $\mathrm{ZnO}$ and $\mathrm{TiO}_{2}$ Combined Activated Carbon Nanocomposite and Adsorption Enhanced Synergetic Photocatalytic Effects. Asian Journal of Chemistry, 26, 1829-1832. DOI: 10.14233/ajchem.2014.15562

[31] Tong, T., Zhang, J., Tian, B., Chen, F., He, D., Anpo, M. (2007). Preparation of Ce-TiO2 catalysts by controlled hydrolysis of titanium alkoxide based on esterification reaction and study on its photocatalytic activity. Journal of colloid and interface science, 315, 382-388. DOI: $10.1016 /$ j.jcis.2007.06.051

[32] Polliotto, V., Albanese, E., Livraghi, S., Agnoli, S., Pacchioni, G., Giamello, E. (2018). Structural, electronic and photochemical properties of cerium-doped zirconium titanate. Catalysis Today, 340, 49-57. DOI: 10.1016/j.cattod.2018.09.026

[33] Tan, I., Ahmad, A., Hameed, B. (2008). Adsorption of basic dye using activated carbon prepared from oil palm shell: batch and fixed bed studies. Desalination, 225, 13-28.

[34] Hameed, B., El-Khaiary, M. (2008). Batch removal of malachite green from aqueous solutions by adsorption on oil palm trunk fibre: equilibrium isotherms and kinetic studies. Journal of Hazardous Materials, 154 (1-3), 237-244. DOI: 10.1016/j.jhazmat.2007.10.017.

[35] Ahmad, T., Rafatullah, M., Ghazali, A., Sulaiman, O., Hashim, R. (2011) Oil palm biomass-Based adsorbents for the removal of water pollutants - A review. Journal of Environmental Science and Health, Part C, 177222 .

[36] Adebisi, G.A., Chowdhury, Z.Z., Alaba, P.A. (2017). Equilibrium, kinetic, and thermodynamic studies of lead ion and zinc ion adsorption from aqueous solution onto activated carbon prepared from palm oil mill effluent. Journal of Cleaner Production, 148, 958-968. DOI: 10.1016/j.jclepro.2017.02.047.

[37] Jia, Q., Lua, A.C. (2008). Concentrationdependent branched pore kinetic model for aqueous phase adsorption. Chemical Engineering Journal, 136, 227-235.

[38] Patsios, S., Sarasidis, V., Karabelas, A. (2013). A hybrid photocatalysisultrafiltration continuous process for humic acids degradation. Separation and Purification Technology, 104, 333-341, DOI: 10.1016/j.seppur.2012.11.033.

[39] Yusof, M.A.M., Seman, M.N.A., Nizam, M. (2016). Polyamide Forward Osmosis Membrane: Synthesis, Characterization and Its
Performance for Humic Acid Removal. Journal of Membrane Science and Research, 2 (2), 90-94. DOI: 10.22079/JMSR.2016.19156.

[40] Haysahi, K.i., Shibata, H., Yui, M., Ohmoto, H. (2001). Experimental Study Assessing the Role of Sedimentary Organic Materials to Control the Redox State of Ground Materials to Control the Redox State of Groundwater: Consumption of Dissolved Oxygen by Humic Acid. Resource Geology, 51 (1), 45-54. DOI: 10.1111/j.1751-3928.2001.tb00080.x.

[41] Szymański, K., Morawski, A.W., Mozia, S. (2016). Humic acids removal in a photocatalytic membrane reactor with a ceramic UF membrane. Chemical Engineering Journal, 305, 19-27. DOI: 10.1016/j.cej.2015.10.024.

[42] Al-Faiyz, Y.S. (2017). CPMAS 13C NMR characterization of humic acids from composted agricultural Saudi waste. Arabian Journal of Chemistry, 10, S839-S853. DOI: 10.1016/j.arabjc.2012.12.018.

[43] Wang, W.X., Onsanit, S., Dang, F. (2012). Dietary bioavailability of cadmium, inorganic mercury, and zinc to a marine fish: Effects of food composition and type. Aquaculture, 356357, 98-104. DOI: 10.1016/j.aquaculture.2012. 05.031 .

[44] Rasidi, R., Jusadi, D., Setiawati, M., Yuhana, M., Zairin, Jr.M., Sugama, K. (2019). Response to Humic Acid Addition Into Feeds with Heavy Metal Content Made of Green Mussels on Growth of Asian Seabass. Biotropia, 26(3). DOI: 10.11598/btb.2019.26.3.1114.

[45] Yang, L., Liu, G., Zheng, M., Jin, R., Zhao, Y., Wu, X. (2017). Pivotal roles of metal oxides in the formation of environmentally persistent free radicals. Environmental Science \& Technology, 51, 12329-12336.

[46] Shan, Z., Wu, J., Xu, F., Huang, F.Q., Ding, H. (2008). Highly effective silver/semiconductor photocatalytic composites prepared by a silver mirror reaction. The Journal of Physical Chemistry C, 112, 1542315428. DOI: $10.1021 / j p 804482 \mathrm{k}$

[47] Tian, Y., Tatsuma, T. (2005). Mechanisms and applications of plasmon-induced charge separation at $\mathrm{TiO}_{2}$ films loaded with gold nanoparticles. Journal of the American Chemical Society, 127, 7632-7637. DOI: $10.1021 / \mathrm{ja} 042192 \mathrm{u}$

[48] Pang, Y.L., Abdullah, A.Z. (2013). Effect of carbon and nitrogen co-doping on characteristics and sonocatalytic activity of $\mathrm{TiO}_{2}$ nanotubes catalyst for degradation of Rhodamine B in water. Chemical Engineering Journal, 214, 129-138. DOI: 10.1016/j.cej.2012.10.036.

[49] Shi, Z.L., Du, C., Yao, S.H. (2011). Preparation and photocatalytic activity of cerium 
doped anatase titanium dioxide coated magnetite composite. Journal of the Taiwan Institute of Chemical Engineers, 42, 652-657. DOI: 10.1016/j.jtice.2010.10.001

[50] Silva, A.M., Silva, C.G., Dražić, G., Faria, J.L. (2009). Ce-doped $\mathrm{TiO}_{2}$ for photocatalytic degradation of chlorophenol. Catalysis Today, 144, 13-18. DOI: 10.1016/j.cattod.2009.02.022
[51] Tbessi, I., Benito, M., Molins, E., LIorca, J., Touati, A., Sayadi, S. (2019). Effect of Ce and Mn co-doping on photocatalytic performance of sol-gel $\mathrm{TiO}_{2}$. Solid State Sciences, 88, 2028. DOI: $10.1016 /$ j.solidstatesciences. 2018.12.004 